\section{AB0781 PSORIATIC ARTHRITIS IN PSORIASIS PATIENTS: RESULTS OF A FRENCH SURVEY}

P. Claudepierre ${ }^{1}$, P. Richebé ${ }^{2}$, S. Benkhalifa ${ }^{3}$, D. Sid Mohand ${ }^{4}$, B. Charles ${ }^{4}$, Y. Braults ${ }^{3}$, M. Lahfa ${ }^{5} \cdot{ }^{1}$ Department of Rheumatology, Université Paris Est Créteil, Chenevier-Mondor Hospital, Créteil; ${ }^{2}$ Department of Rheumatology, Université Paris Est Créteil, Chenevier-Mondor Hospital; ${ }^{3}$ Pfizer; ${ }^{4}$ France Psoriasis, Paris; ${ }^{5}$ Private dermatology practice, Biarritz, France

Background: Early detection of psoriatic arthritis (PsA) in patients with skin psoriasis (Pso) is critical to reduce the risk of joint damage, disability, and comorbidities. However PsA is mostly under-diagnosed in patients with Pso. Objectives: first to compare characteristics of patients with Pso without PsA with those of patients with Pso and PsA, then to compare patients with Pso and potential but undiagnosed PsA (puPsA) to the other patients.

Methods: 817 patients completed an online questionnaire published by the French Psoriasis Patients Association, including multiple-choice questions regarding in particular past and current symptoms. For analysis, a first comparison was performed between patients with Pso without known PsA and patients with Pso and PsA, then between patients with symptoms suggestive of PsA (puPsA group), i.e., patients with past or current joint or back pain accompanied by waking up at night and/or morning stiffness, with PsA patients on the one hand, and with patients without known PsA and without symptoms suggestive of puPsA, on the other hand.

Results: 746 patients reported having Pso of which 192 (25.7\%) had also PsA. Among the 554 patients without known PsA, 190 (34.3\%) had symptoms suggestive of PsA, 101 (18.2\%) had rheumatologic symptoms not suggestive of PsA, and $263(47.5 \%)$ had no rheumatologic symptoms. The comparison, in multivariate analysis, between patients with Pso and PsA and patients with Pso without known PsA showed significant differences $(p<0.05)$ : Pso and PsA patients had more often current bone or joint pain at any time (OR=7.8), joint pain during the day $(\mathrm{OR}=2.45)$, stiff back or joints on waking $(\mathrm{OR}=1.77)$, painful and swollen fingers and toes $(\mathrm{OR}=3.15)$, past joint pain during the day $(\mathrm{OR}=3.05)$, and drug in tablet form $(\mathrm{OR}=2.07)$, biotherapy alone $(\mathrm{OR}=5.45)$ or with DMARDs $(\mathrm{OR}=16.06)$; conversely they had less often guttate psoriasis $(\mathrm{OR}=0.54)$. Results of the multivariate analysis comparing patients with puPsA to the other patients are shown in Tables 1 and 2 (comparison with patients with Pso and PsA in Table 1; comparison with patients with Pso without known PsA in Table 2).

Table 1. Multivariate analysis, patients with puPsA and Pso compared with patients with Pso and PSA

\begin{tabular}{lc}
\hline Covariates $(p<0.05$ for all OR) & OR $[95 \% \mathrm{Cl}]$ \\
\hline Current skin pain & $\mathrm{OR}=1.85[1.12 ; 3.08]$ \\
Current bone or joint pain & $\mathrm{OR}=0.25[0.15 ; 0.44]$ \\
Current joint pain during the day & $\mathrm{OR}=0.49[0.29 ; 0.84]$ \\
Current back pain & $\mathrm{OR}=2.55[1.52 ; 4.29]$ \\
Current painful and swollen fingers and toes & $\mathrm{OR}=0.29[0.17 ; 0.51]$ \\
Past joint pain during the day & $\mathrm{OR}=0.39[0.19 ; 0.79]$ \\
Biotherapy/Neither biotherapy nor DMARD & $\mathrm{OR}=0.28[0.12 ; 0.67]$ \\
Biotherapy + DMARD/Neither biotherapy nor DMARD & $\mathrm{OR}=0.15[0.04 ; 0.55]$ \\
\hline
\end{tabular}

Table 2. multivariate analysis, patients with Pso without known PsA compared with patients with puPsA

\begin{tabular}{ll}
\hline Covariates $(\mathrm{p}<0.05$ for all OR) & $\mathrm{OR}[95 \% \mathrm{Cl}]$ \\
\hline Current nail changes & $\mathrm{OR}=1.53[1.02 ; 2.29]$ \\
Current fatigue & $\mathrm{OR}=2.53[1.72 ; 3.72]$ \\
Other current symptoms & $\mathrm{OR}=0.33[0.18 ; 0.60]$ \\
Hydration & $\mathrm{OR}=1.48[1.01 ; 2.18]$ \\
\hline
\end{tabular}

Conclusions: That survey on Pso patients showed that a fourth of them also had PsA, but more importantly that about another fourth had puPsA, highlighting the underdiagnosis of PsA. It suggests that presence of fatigue and nail changes might raise suspicion of PsA in Pso patients.

Disclosure of Interest: P. Claudepierre Grant/research support from: AbbVie, MSD, Roche, Pfizer, Consultant for: AbbVie, BMS, Celgene, Janssen, MSD, Novartis, Pfizer, Roche, UCB, P. Richebé: None declared, S. Benkhalifa: None declared, D. Sid Mohand: None declared, B. Charles: None declared, Y. Braults: None declared, M. Lahfa Consultant for: investigator or speaker for AbbVie, MSD, Celgene, Janssen, Novartis, Pfizer, Roche, Takeda, UCB, Lilly, Leo Pharma, Galderma, Astellas, Pierre Fabre. Dermatology.

DOI: 10.1136/annrheumdis-2017-eular.2397

\section{AB0782 PSORIATIC ARTHRITIS EARLY ULTRASONOGRAPHIC CHANGES IN PATIENTS WITH PSORIASIS AND NAIL PSORIASIS. A COMPARATIVE STUDY WITH SUBJECTS WITHOUT PSORIASIS}

$\underline{\text { P. Rodriguez Henriquez }}^{1}$, M.L. Cardenas-Hernandez ${ }^{2}$, L. Lammoglia-Ordiales ${ }^{2}$ L.T. Becerril-Mendoza ${ }^{3}$, R.M. Lacy-Niebla ${ }^{2} .{ }^{1}$ Rheumatology; ${ }^{2}$ Dermatology, Hospital General Dr. Manuel Gea González; ${ }^{3}$ Rheumatology, Hospital Juarez de Mexico, Mexico, Mexico

Background: Psoriatic Arthritis (PsA) has a prevalence of $30 \%$ amongst Psoriasis (Ps)patients. However in patients with ungueal Ps the prevalence has been reported in up to $68 \%$ of cases. In muskuloskeletal ultrasound (MSUS) studies the lesion most frequently reported is enthesitis followed by synovitis in early PsA patients.

Objectives: To determine the presence of psoriatic arthritis early ultrasonographic changes in patients with psoriasis, nail psoriasis, and subjects without psoriasis. Methods: Analytic, comparative, prospective and transversal study, in which patients with psoriasis, nail psoriasis, and subjects without psoriasis paired by age, were recruited. Each group underwent a skin and joint checkup, which included demographic data, comorbidities, psoriasis severity and joint signs and symptoms. The ultrasonographic evaluation consisted in a gray scale detection and classification according to severity scales, of synovitis, enthesitis, synovial effusion and bone erosions in the distal interphalangeal joints of both hands.

Results: A total of 16 patients, 8 with psoriasis and 8 with nail psoriasis, as well as 9 subjects without psoriasis, were recruited. The psoriasis group included mostly men $(87.5 \%)$, unlike the subjects without psoriasis $(44.4 \%)$ and the nail psoriasis group $(37.5 \%)(p=0.09)$. The mean age for the study population was $55.16+$ 8.09 years. There was no statistical significance between groups $(p=0.430)$. The greatest prevalence of comorbidities was found in both groups with psoriasis. The mean time of disease duration in the nail psoriasis group was $20.12+14.54$ years, vs $13.37+14.45$ years in the psoriasis group $(p=0.247)$. Synovitis was found in $100 \%$ of patients in the psoriasis group, vs $37.5 \%$ in the nail psoriasis group, and $62.5 \%$ in the subjects without psoriasis group $(\mathrm{p}=0.028)$. No enthesitis was observed in any group

\begin{tabular}{|c|c|c|c|c|}
\hline & Synovitis & Grade 1 & Grade 2 & Grade 3 \\
\hline $\begin{array}{l}\text { Control } \\
\text { group }\end{array}$ & $62.5 \%$ & $12.5 \%$ & $37.5 \%$ & $12.5 \%$ \\
\hline $\begin{array}{l}\text { Ungueal } \\
\text { Psoriasis }\end{array}$ & $37.5 \%$ & $62.5 \%$ & $25 \%$ & $12.5 \%$ \\
\hline Psoriasis & $100 \%$ & $25 \%$ & $50 \%$ & $12.5 \%$ \\
\hline
\end{tabular}

Conclusions: Synovitis was more frequent than enthesitis in our population as an ultrasonographic finding of psoriatic arthritis. No association was found between other variables with synovitis, such as age, sex, disease duration and comorbidities.

References:

[1] Raposo I, Torres T. Nail psoriasis as a predictor of the development of psoriatic arthritis. Actas Dermosifiliogr 2015;106(6):452-457.

[2] Busse K, Liao W. Which Psoriasis Patients Develop Psoriatic Arthritis? Psoriasis Forum 2010;16(4):17-25.

[3] Gladman DD, Antoni C, Mease P, Clegg DO, Nash P. Psoriatic arthritis: epidemiology, clinical features, course, and outcome. Ann Rheum Dis 2005;64(2):ii14-ii17.

[4] Ibrahim G, Waxman R, Helliwell PS. The Prevalence of Psoriatic Arthritis in People With Psoriasis. Arthritis \& Rheumatism (Arthritis Care \& Research) 2009;61(10):1373-1378.

[5] Naredo E, Möller I, De Miguel E, et al. High prevalence of ultrasonographic synovitis and enthesopathy in patients with psoriasis without psoriatic arthritis: a prospective case-control study. Rheumatology (Oxford) 2011;50 (10):18381848.

Disclosure of Interest: None declared

DOI: 10.1136/annrheumdis-2017-eular.5552

\section{AB0783 THE RELATIONSHIP BETWEEN THE DEGREE OF SKIN INVOLVEMENT AND JOINT ACTIVITY IN PATIENTS WITH PSA: EXPERIENCE FROM THE CORRONA REGISTRY}

$\underline{\text { P.J. Mease }}^{1}$, C.J. Etzel ${ }^{2,3}$, J.R. Lisse ${ }^{4}$, A.W. Armstrong ${ }^{5}$, W.J. Huster ${ }^{4}$, S. Rebello $^{2}$, R. Dodge ${ }^{2}$, T. Muram ${ }^{4}$, S. Al Sawah-Folian ${ }^{4}$, M.J. Murage ${ }^{4}$, J.D. Greenberg ${ }^{2,6}$, W. Malatestinic ${ }^{4}$. ' Swedish Medical Center, University of Washington School of Medicine, Seattle; ${ }^{2}$ Corrona, LLC, Southborough; ${ }^{3}$ UT MD Anderson, Houston; ${ }^{4}$ Eli Lilly and Company, Indianapolis: ${ }^{5}$ University of Southern California, Los Angeles; ${ }^{6}$ NYU School of Medicine, New York, United States

Background: Prior studies have shown inconsistent relationships between skin and joint symptoms in patients with comorbid psoriasis ( $\mathrm{PsO}$ ) and psoriatic arthritis $(\mathrm{PsA})^{1-3}$

Objectives: To characterize the relationship between skin severity and joint activity in patients with comorbid PsA and $\mathrm{PsO}$ at enrollment.

Methods: Data from the U.S. Corrona PsA/spondyloarthritis (PsA/SpA) registry were obtained from the period $3 / 21 / 2013-9 / 30 / 2016$. Inclusion criteria included a diagnosis of $\mathrm{PsA}$, a history of $\mathrm{PsO}$, and age greater than 18 years. PsA patients were evaluated for skin severity as defined by Body Surface Area (BSA) and joint activity as defined by the level of clinical disease activity index (CDAI). Patient characteristics, including current and prior PsA medication use, were obtained during the enrollment visit. We evaluated the relationship of skin severity (BSA) and joint activity (CDAI) with multi-variable linear regression.

Results: 1,542 patients met inclusion criteria: $52.9 \%$ were women with mean (SD) age 53.7 (13.2) years, with median 9.0 years PsA disease duration, and 71 (4.6\%) with fibromyalgia. $266(18 \%)$ patients were on no DMARD therapy, $430(29 \%)$ 